\title{
ß-Ecdysone Augments Peak Bone Mass in Mice of Both Sexes
}

\author{
Weiwei Dai PhD, HongLiang Zhang MD, PhD, Zhendong A. Zhong PhD, \\ Li Jiang MD, Haiyan Chen MS, Yu-An Evan Lay MS, Alexander Kot BS, \\ Robert O. Ritchie PhD, Nancy E. Lane MD, Wei Yao MD
}

Published online: 31 March 2015

(C) The Association of Bone and Joint Surgeons (B) 2015

\begin{abstract}
Background One of the strongest predictors for osteoporosis is peak bone mass. Interventions to augment peak bone mass have yet to be developed. $\beta$-Ecdysone ( $\beta$ Ecd), a natural steroid-like compound produced by arthropods to initiate metamorphosis, is believed to have androgenic effects and so may be used to augment bone mass.

Questions/purposes The purpose of this study was to use both male and female (1) gonadal-sufficient; and (2) -insufficient mice to investigate sex differences in terms of bone development and structure after $\beta$ Ecd administration.
\end{abstract}

Two of the authors (WD, HZ) contributed equally to this manuscript. This work was funded by a National Institutes of Health grant R01 AR061366 (WY), 1P50AR063043 (NEL), K24 AR048841 (NEL), and the endowed chair for aging at UC Davis (NEL).

All ICMJE Conflict of Interest Forms for authors and Clinical Orthopaedics and Related Research ${ }^{\circledR}$ editors and board members are on file with the publication and can be viewed on request.

Clinical Orthopaedics and Related Research ${ }^{\mathbb{R}}$ neither advocates nor endorses the use of any treatment, drug, or device. Readers are encouraged to always seek additional information, including FDAapproval status, of any drug or device prior to clinical use.

Each author certifies that his or her institution approved the animal protocol for this investigation and that all investigations were conducted in conformity with ethical principles of research. This work was performed at the UC Davis Medical Center, Sacramento, CA, USA.

\section{W. Dai}

Department of Science and Technology, Integrative Medicine Discipline, Longhua Hospital Shanghai University of Traditional Chinese Medicine, Shanghai, PR China

W. Dai, H. Zhang, Z. A. Zhong, L. Jiang, H. Chen, Y.-A. E. Lay, A. Kot, N. E. Lane, W. Yao ( $\square)$ Center for Musculoskeletal Health, Internal Medicine, University of California at Davis Medical Center, 4800 2nd Avenue, Suite 2004, Sacramento, CA 95817, USA

e-mail: Yao@ucdavis.edu; wei.yao@ucdmc.ucdavis.edu
Methods Two-month-old male and female Swiss-Webster mice were randomized to receive either vehicle or $\beta$ Ecd $(0.5 \mathrm{mg} / \mathrm{kg})$ for 3 weeks. In a separate experiment to evaluate the effects of $\beta$ Ecd on sex hormone-deficient mice, gonadectomy was performed in male (orchiectomy $[\mathrm{ORX}]$ ) and female mice (ovariectomy [OVX]). Shamoperated and the ORX/OVX mice were then treated for 3 weeks with $\beta E c d$. Primary endpoints for the study were trabecular bone structure and bone strength.

Results In male mice, the trabecular bone volume was $0.18 \pm 0.02$ in the placebo-treated (PL) and $0.23 \pm 0.02$ in the $\beta$ Ecd-treated group $(\mathrm{p}<0.05$ versus $\mathrm{PL})$; and $0.09 \pm 0.01$ in the ORX group $(\mathrm{p}<0.05$ versus $\mathrm{PL})$ and $0.12 \pm 0.01$ in the ORX $+\beta$ Ecd group. Vertebral bone strength (maximum load) was $43 \pm 2$ in PL and $51 \pm 1$ in the $\beta$ Ecd-treated group $(\mathrm{p}<0.05$ versus PL); and $30 \pm 4$ in the ORX group ( $<<0.05$ versus PL) and $37 \pm 3$ in the ORX $+\beta$ Ecd group. In female mice, trabecular bone volume was $0.23 \pm 0.02$ in PL and $0.26 \pm 0.02$ in the $\beta$ Ecd-treated group ( $\mathrm{p}<0.05$ versus PL); and $0.15 \pm 0.01$ in the OVX group ( $p<0.05$ versus PL) and $0.14 \pm 0.01$ in the OVX $+\beta E c d$ group. Maximum load of the vertebrae was $45 \pm 2$ in $\mathrm{PL}$ and $48 \pm 4$ in the $\beta$ Ecd-treated group; and $39 \pm 4$ in the OVX group ( $<0.05$ versus PL) and $44 \pm 4$ in the OVX $+\beta$ Ecd group.

\section{H. Zhang}

Department of Emergency, Second Affiliated Xiangya Hospital, Central South University, Changsha, PR China

L. Jiang

Department of Emergency, First Affiliated Hospital, Dalian Medical School, Dalian, PR China

R. O. Ritchie

Department of Materials Science and Engineering, University of California at Berkeley, Berkeley, CA, USA 
Conclusions These findings suggest the potential use of $\beta E c d$ in the augmentation of bone mass in growing male and female mice. It may also partially prevent the detrimental effects of gonadectomy on trabecular bone.

Clinical Relevance Our results support the potential use of $\beta E c d$ or nature products that are rich in $\beta E c d$ to augment peak bone mass. $\beta$ Ecd may differ from the other anabolic hormone treatments that may have severe side effects such as serious cardiac complications. However, its effects on humans remain to be determined.

\section{Introduction}

Peak bone mass (PBM) is defined as the maximum amount of bone tissue that is presented at the end of skeletal maturation. PBM is dependent on the rate of bone growth, which is highest during infancy and the pubertal growth period. Adolescence is a particularly critical period of bone acquisition, because the rate of bone growth nearly doubles that of the earlier years, and approximately $40 \%$ of the new adolescent bone comes from periosteal expansion. At the end of puberty, the epiphyseal growth plates fuse and linear bone growth ends. However, bone growth continues at the endocortical and trabecular bone surfaces and $90 \%$ to $95 \%$ of the PBM is acquired by 20 years of age [22]. Epidemiological studies have shown that males have higher PBM than females, which may delay the osteoporosis development in males until their eighth decade of life [2, 5, 16]. Although sex differences in PBM are largely predisposed by genetic determinants in rodents [31] and humans [32], increased physical activities during the prepubertal period may alter PBM. In boys, regular exercise is associated with higher bone mineral density assessed at the spine, femoral neck, and total body, whereas in girls, bone mineral density is associated more with winter sunlight exposure [23]. Although weightbearing exercise and the intake of calcium and vitamin D intake through diet and supplements during puberty have a modest impact on the augmentation of PBM [6, 11, 29, 39], interventions with greater efficacy have yet to be developed.

During puberty, serum estrogen levels increase in females. Estrogen has a number of effects on bone cell activity including periosteal apposition inhibition, endosteal bone resorption, and chondrocyte remodeling. These effects result in epiphyseal closure and attenuate periosteal expansion [10]. During puberty in males, serum levels of estrogen also increase, resulting in periosteal expansion through estrogen receptor $\alpha$, whereas androgen acts on osteoblasts and osteocytes through androgen receptor to increase trabecular bone formation [27]. Hormones largely regulate skeleton development, but the direct use of hormones in the growing skeleton is limited as a result of their negative effects such as tumorigenesis in the reproductive system [26, 33]. Additionally, there are other pitfalls associated with using anabolic hormones in adults such as severe cardiac and other complications [28, 34]. Therefore, we chose to investigate naturally derived products to increase PBM.

One of these naturally derived products is $\beta$-Ecdysone $(\beta E c d)$, which is produced by arthropods to initiate metamorphosis, the so-called molting process [36]. A number of plants produce ecdysteroids that protect them from herbivores $[14,15]$. Achyranthes root (Niu xi) is one of the Chinese medicinal herbs often used to treat low back pain, circulatory disorders, and aging [4, 8, 17]. Achyranthes extracts are highly rich in $\beta \mathrm{Ecd}$ [7]. The latter is reported to stimulate muscular growth in rodents $[3,9,18]$ and increase the growth plate width in estrogen-deficient rats [24].

The purpose of this study was to use both male and female (1) gonadal-sufficient; and (2) insufficient mice to investigate sex differences in terms of bone development and structure after $\beta E c d$ administration.

\section{Materials and Methods}

\section{Animals and Experimental Procedures}

Two-month-old male and female Swiss-Webster mice were purchased from Jackson Laboratory and housed in the vivarium in UC Davis Medical Center. The mice were randomized into groups with eight to 11 per group: Group 1 , male controls treated with phosphate-buffered saline (vehicle; Male); Group 2, males treated with $\beta E c d$ (Male $+\beta$ Ecd $0.5 \mathrm{mg} / \mathrm{kg}, 5 \times /$ week); Group 3, female controls treated with phosphate-buffered saline (vehicle; Female); Group 4, females treated with $\beta E c d$ (Female $+\beta$ Ecd $0.5 \mathrm{mg} / \mathrm{kg}, 5 \times /$ week). The $\beta$-Ecd dose was chosen from a pilot dose-response study we performed on male mice with doses of 0.25 to $1 \mathrm{mg} / \mathrm{kg}$ [12].

The mice were euthanized after 3 weeks of treatment at 3 months of age. All of the mice were maintained on commercial rodent chow (22/5 Rodent Diet; Teklad, Madison, WI, USA) ad libitum with $0.95 \%$ calcium and $0.67 \%$ phosphate. The mice were housed in a room that was maintained at $20^{\circ} \mathrm{C}$ with a 12-hour light/dark cycle. In a separate experiment to evaluate the effects of $\beta E c d$ on sex hormone-deficient mice, a gonadectomy was performed in male (orchiectomy [ORX]) and female (ovariectomy [OVX]) mice. Sham-operated and the ORX/OVX mice were then treated with $\beta E c d 0.5 \mathrm{mg} / \mathrm{kg}$, $5 \times /$ week for 3 weeks. $\beta$ Ecd was purchased from Sigma Aldrich (molecular weight $=480.6$, with purity $\geq 98 \%$ ). Calcein (Sigma Aldrich, St Louis, MO, USA) was injected at $20 \mathrm{mg} / \mathrm{kg}$ to all mice 7 and 2 days before euthanasia, respectively. All animals were treated according to the USDA animal 
care guidelines with the approval of the UC Davis Committee on Animal Research.

Micro-CT Measurements of Bone Architecture and Mineral Density of Bone Tissue

The fifth lumbar vertebrae were scanned and measured using the VivaCT 40 (Scanco Medical AG, Bassersdorf, Switzerland) at an energy level of $70 \mathrm{KeV}$ and intensity of $145 \mu \mathrm{A}$ with a voxel resolution of $10 \mu \mathrm{m}$ in all three spatial dimensions. The entire lumbar vertebra was scanned and the trabecular bone juxtaposed to both the cranial and caudal growth plates and the cortex was evaluated. The gray-scale images were segmented using a constrained three-dimensional Gaussian filter (sigma, 0.8; support, 1.0; fixed threshold of 240) to extract the structure of the mineralized tissue to obtain trabecular bone volume and thickness [25, 42]. For the right midfemur, the scanning was performed at the middle femur continuing proximally $1 \mathrm{~mm}$. All the slices were used to evaluate cortical bone volume and cortical bone thickness [19, 45, 46].

\section{Biochemical Methods}

Serum levels for bone turnover markers, osteoprotegerin, osteocalcin, and Dkk1 were measured using a luminex multiplex bone panel assay (EMD Millipore, Billerica, MA, USA) and serum CTX-1 was measured by enzyme-linked immunosorbent assay (Immunodiagnostic Systems Inc, Gaithersburg, MD, USA) following the manufacturer's instructions.

\section{Cryostat Section for Bone Formation Measurements}

The first and second lumbar vertebrae were used for cryostat sectioning. The samples were fixed in fresh $4 \%$ paraformaldehyde on ice for 4 hours and then transferred to $30 \%$ sucrose overnight. The sections $(8 \mu \mathrm{m})$ were obtained using a Leica microtome coupled with a tape transfer system (Leica Microsystems Inc, Buffalo Grove, IL, USA). The middle right femurs were embedded in methyl methacrylate and sectioned to $30 \mu \mathrm{m}$ using a Leica SP1600 microtome (Leica Microsystems Inc). Bone histomorphometry was performed using the Bioquant imaging analysis system (Bioquant Image Analysis Corporation, Nashville, TN, USA) [19, 45, 46]. Lumbar vertebral samples from all groups and only FX from the intact groups were evaluated for bone histomorphometry. Bone histomorphometry was not performed for the cortical bone from the ORX and OVX $+\beta$ Ecd treatment groups as a result of the lack of structural and bone strength changes measured by micro-CT and mechanical testing.
Biomechanical Testing

The lumbar vertebral compression and the left femurs three-point bending tests were performed using an MTS 831 electro-servo-hydraulic testing system (MTS Systems Corp, Eden Prairie, MN, USA) at a displacement rate of $0.01 \mathrm{~mm} / \mathrm{s}$ with a $90-\mathrm{N}$ load cell. Values for the maximum load were determined. A measure of work to failure was estimated by calculating the area under the load versus displacement curve [19, 37, 44, 45].

\section{Statistical Methods}

Sample size calculation was estimated from our published data on glucocorticoid-induced (GC) bone loss using trabecular bone volume as our primary endpoint. Mean trabecular bone volume for the placebo-treated (PL) group was $12 \%$, in GC was $10 \%$, and sigma was $2 \%$. The effective sample size to have $80 \%$ power and alpha 0.05 was eight animals per group. Means and SDs were calculated for all parameters from all groups. Two-way analysis of variance was used to investigate the main effects of sex, treatments, and their interactions. Bonferroni post hoc tests were used to make comparisons between the groups (SPSS Version 18; SPSS Inc, Chicago, IL, USA; GraphPad Prism, La Jolla, CA, USA). $\mathrm{p}<0.05$ was considered significant.

\section{Results}

Does $\beta$ Ecd Treatment Affect Overall Well-being of the Mice?

Male mice weighed $31 \mathrm{~g}$ at the beginning (Day 0) of the study and were $36 \mathrm{~g}$ at the end $(\mathrm{p}<0.05$ from Day 0) when they were 11 weeks of age. Baseline body weight for the female mice was $25 \mathrm{~g}$ and they weighed $28 \mathrm{~g}$ at 11 weeks. ORXed mice did not gain body weight over the study period, whereas OVXed mice's body weights increased from $25 \mathrm{~g}$ to $29 \mathrm{~g}$ and was similar to the shamoperated mice. $\beta E c d$ treatment did not alter body mass changes in the male or female mice (Table 1).

Does $\beta$ Ecd Treatment Affect Bone Turnover and Bone Structures?

\section{Serum Bone Turnover Marker Changes}

In male mice, serum osteocalcin was $5.1 \pm 1.6$ in PL and $6.5 \pm 1.5$ in $\beta$ Ecd-treated group; and $13 \pm 1.4$ in the ORX group ( $\mathrm{p}<0.05$ versus $\mathrm{PL}$ ) and $15 \pm 1.2$ in the ORX + 
$\beta$ Ecd group. Serum CTX-1 did not change among the groups. In female mice, serum osteocalcin was $12 \pm 2.6$ in $\mathrm{PL}$ and $12 \pm 1.5$ in the $\beta$ Ecd-treated group; and $14 \pm 3.1$ in the OVX group and $14 \pm 1.2$ in the OVX $+\beta E c d$ group. Serum CTX-1 was $19 \pm 3.4$ in PL and $16 \pm 3.0$ in the $\beta$ Ecd-treated group; and $24 \pm 1.6$ in the OVX group $(\mathrm{p}<0.05$ versus PL) and $20 \pm 2.3$ in the OVX $+\beta$ Ecd group ( $<<0.05$ versus OVX) (Table 2$)$.

\section{Effects of $\beta E c d$ on Trabecular Bone Formation and Resorption}

In male mice, the mineralizing surface was $24 \pm 6.9$ in PL and $33 \pm 1.1$ in the $\beta E c d$-treated group ( $p<0.05$ versus $\mathrm{PL}$ ); and $26 \pm 4.1$ in the ORX group and $28 \pm 4.3$ in the ORX $+\beta E c d$ group. In female mice, MS/BS did not change among the groups.

In male mice, the surface-based bone formation rate was $0.45 \pm 0.1$ in PL and $0.61 \pm 0.2$ in the $\beta$ Ecd-treated group

Table 1. Body weight changes (mean \pm SD)

\begin{tabular}{lll}
\hline Treatment groups & $\begin{array}{l}\text { Day 0/8 weeks } \\
\text { old }(\mathrm{g})\end{array}$ & $\begin{array}{l}\text { Day 21/ 11 weeks } \\
\text { old }(\mathrm{g})\end{array}$ \\
\hline Male & & \\
$\quad$ Male + vehicle & $31 \pm 1.7$ & $36 \pm 1.0$ \\
Male $+\beta$-ecdysone & $32 \pm 1.3$ & $36 \pm 1.6$ \\
ORX + vehicle & $31 \pm 1.2$ & $31 \pm 0.8^{*}$ \\
ORX $+\beta$-ecdysone & $31 \pm 1.3$ & $30 \pm 0.9^{*}$ \\
Female & & \\
Female + vehicle & $25 \pm 0.4^{\dagger}$ & $28 \pm 0.5$ \\
Female $+\beta$-ecdysone & $25 \pm 0.3$ & $28 \pm 1.5$ \\
OVX + vehicle & $25 \pm 0.3$ & $29 \pm 0.8^{*}$ \\
OVX $+\beta$-ecdysone & $25 \pm 0.7$ & $29 \pm 0.9^{*}$ \\
\hline
\end{tabular}

$* \mathrm{p}<0.05$ for ORX/OVX versus sham; ${ }^{\dagger} \mathrm{p}<0.05$ for sex difference; ORX = orchiectomy; OVX = ovariectomy.
( $\mathrm{p}<0.05$ versus PL); and $0.61 \pm 0.2$ in the ORX group $(\mathrm{p}<0.05$ versus PL) and $0.69 \pm 0.1$ in the $\mathrm{ORX}+\beta \mathrm{Ecd}$ group. In female mice, the BFR/BS was $0.64 \pm 0.2$ in PL and $0.86 \pm 0.3$ in the $\beta E c d-$ treated group; and $0.66 \pm 0.2$ in the OVX group and $0.82 \pm 0.2$ in the OVX $+\beta E c d$ group ( $\mathrm{p}<0.05$ versus OVX) (Table 2 ).

The osteoclast surface did not change among the treatment groups in male mice. Oc/BS was $0.57 \pm 0.1$ in PL and $0.61 \pm 0.1$ in the $\beta$ Ecd-treated group; and $0.91 \pm 0.1$ in the OVX group ( $p<0.05$ versus PL) and $0.78 \pm 0.01$ in the OVX $+\beta$ Ecd group $(\mathrm{p}<0.05$ versus OVX) (Table 2 ).

\section{Effects of $\beta E c d$ on Trabecular Bone Structures}

In male mice, the $\mathrm{BV} / \mathrm{TV}$ was $0.18 \pm 0.02$ in $\mathrm{PL}$ and $0.23 \pm 0.02$ in the $\beta E c d-t r e a t e d$ group $(p<0.05$ versus $\mathrm{PL}$ ); and $0.09 \pm 0.01$ in the ORX group ( $\mathrm{p}<0.05$ versus $\mathrm{PL})$ and $0.12 \pm 0.01$ in the ORX $+\beta E c d$ group. In female mice, BV/TV was $0.23 \pm 0.02$ in PL and $0.26 \pm 0.02$ in the $\beta E c d-t r e a t e d$ group $(p<0.05$ versus $P L) ;$ and $0.15 \pm 0.01$ in the OVX group ( $p<0.05$ versus PL) and $0.14 \pm 0.01$ in the OVX $+\beta$ Ecd group (Fig. 1).

\section{Effects of $\beta E c d$ on Cortical Bone Formation in Gonadal-sufficient Mice}

In male mice, bone formation at the periosteal bone surface was $1.31 \pm 0.1$ in PL and $1.80 \pm 0.3$ in the $\beta E c d$-treated group ( $\mathrm{p}<0.05$ versus PL). In female mice, Ps-BFR was $1.1 \pm 0.1$ in PL and $1.7 \pm 0.2$ in the $\beta$ Ecd-treated group ( $\mathrm{p}<0.05$ versus PL) (Fig. 2). In male mice, bone formation at the endocortical bone surface was $0.9 \pm 0.1$ in PL and $2.6 \pm 0.3$ in the $\beta$ Ecd-treated group $(\mathrm{p}<0.05$ versus PL). In female mice, Ec-BFR was $1.4 \pm 0.1$ in PL and

Table 2. Bone turnover changes (mean $\pm \mathrm{SD}$ )

\begin{tabular}{|c|c|c|c|c|c|}
\hline Treatment groups & Osteocalcin $(\mu \mathrm{g} / \mathrm{mL})$ & CTX-1 (ng/mL) & MS/BS (\%) & $\mathrm{BFR} / \mathrm{BS}\left(\mu \mathrm{m} 3 / \mu \mathrm{m}^{2} / \mathrm{day}\right)$ & Oc/BS (number/mm) \\
\hline \multicolumn{6}{|l|}{ Male } \\
\hline Male & $5.1 \pm 1.6$ & $23 \pm 1.7$ & $24 \pm 6.9$ & $0.45 \pm 0.1$ & $0.60 \pm 0.1$ \\
\hline Male $+\beta$-ecdysone & $6.5 \pm 1.5$ & $21 \pm 5.0$ & $33 \pm 1.1^{*}$ & $0.61 \pm 0.2^{*}$ & $0.59 \pm 0.1$ \\
\hline ORX + vehicle & $13 \pm 1.4^{*}$ & $26 \pm 2.5$ & $26 \pm 4.1$ & $0.61 \pm 0.2 *$ & $0.66 \pm 0.1$ \\
\hline ORX $+\beta$-Ecdysone & $15 \pm 1.2 *$ & $25 \pm 2.7$ & $28 \pm 4.3$ & $0.69 \pm 0.1$ & $0.62 \pm 0.1$ \\
\hline \multicolumn{6}{|l|}{ Female } \\
\hline Female & $12 \pm 2.6^{\dagger}$ & $19 \pm 3.4$ & $26 \pm 4.8$ & $0.64 \pm 0.2^{\dagger}$ & $0.57 \pm 0.1$ \\
\hline Female $+\beta$-ecdysone & $12 \pm 1.5^{\dagger}$ & $16 \pm 3.0$ & $35 \pm 10.3$ & $0.86 \pm 0.3$ & $0.61 \pm 0.1$ \\
\hline OVX + vehicle & $14 \pm 3.1$ & $24 \pm 1.6^{*}$ & $29 \pm 8.3$ & $0.66 \pm 0.2$ & $0.91 \pm 0.1^{*}$ \\
\hline OVX $+\beta$-ecdysone & $14 \pm 1.2$ & $20 \pm 2.3^{*}$ & $34 \pm 9.1$ & $0.82 \pm 0.2^{*}$ & $0.78 \pm 0.0^{*}$ \\
\hline
\end{tabular}

${ }^{*} \mathrm{p}<0.05$ for ORX/OVX versus sham; ${ }^{\dagger} \mathrm{p}<0.05$ for sex difference; ${ }^{*} \mathrm{p}<0.05$ treatment effect within the same sex; MS/BS $=$ mineralizing surface; $\mathrm{BFR} / \mathrm{BS}=$ surface-based bone formation rate; Oc/BS $=$ osteoclast/bone surface; ORX = orchiectomy; OVX $=$ ovariectomy. 


\section{Trabecular Bone Volume (BV/TV)}

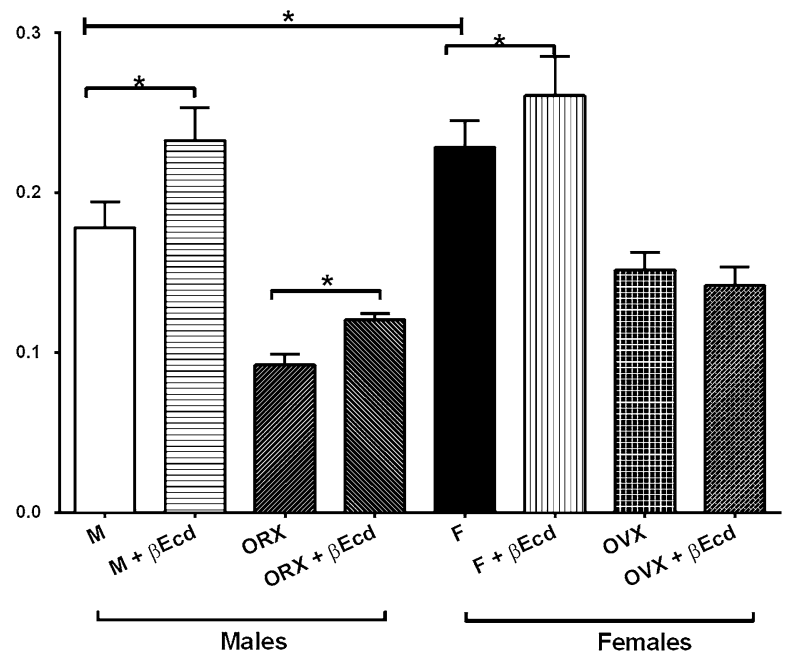

Maximum Load (N)

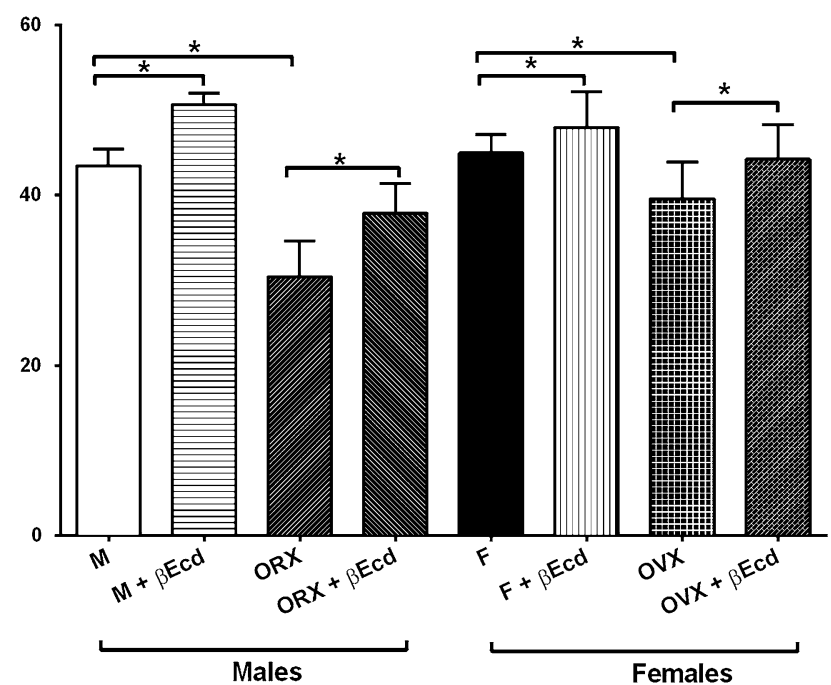

Fig. $1 \beta$ Ecd treatment increases vertebral trabecular bone volume and bone strength. Two-month-old male or female mice were treated with $\beta E c d$ for 21 days. Lumbar vertebral trabecular bone (LVB)

$3.2 \pm 0.4$ in the $\beta E c d$-treated group $(\mathrm{p}<0.05$ versus PL) (Fig. 2).

\section{Effects of $\beta E c d$ on Cortical Bone Structure}

In male mice, cortical bone volume was $0.80 \pm 0.02$ in PL and $0.88 \pm 0.03$ in the $\beta$ Ecd-treated group ( $\mathrm{p}<0.05$ versus PL); and $0.74 \pm 0.02$ in the ORX group $(\mathrm{p}<0.05$ versus PL) and $0.74 \pm 0.01$ in the ORX $+\beta E c d$ group ( $p<0.05$ versus PL). In female mice, cortical BV was

\section{Trabecular Thickness (mm)}

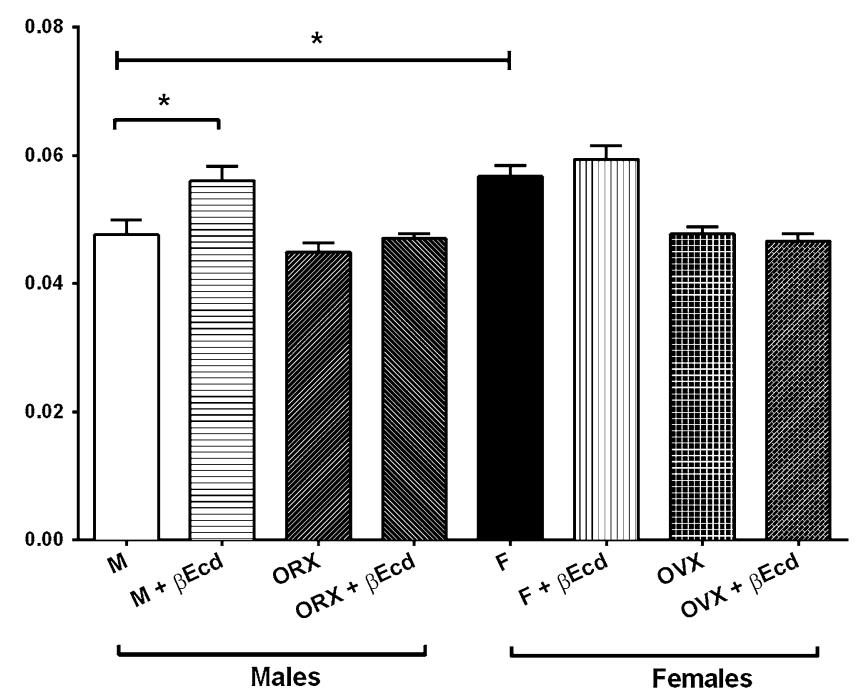

Work to Fracture $\left(\mathrm{N}^{*} \mathrm{~mm}\right)$

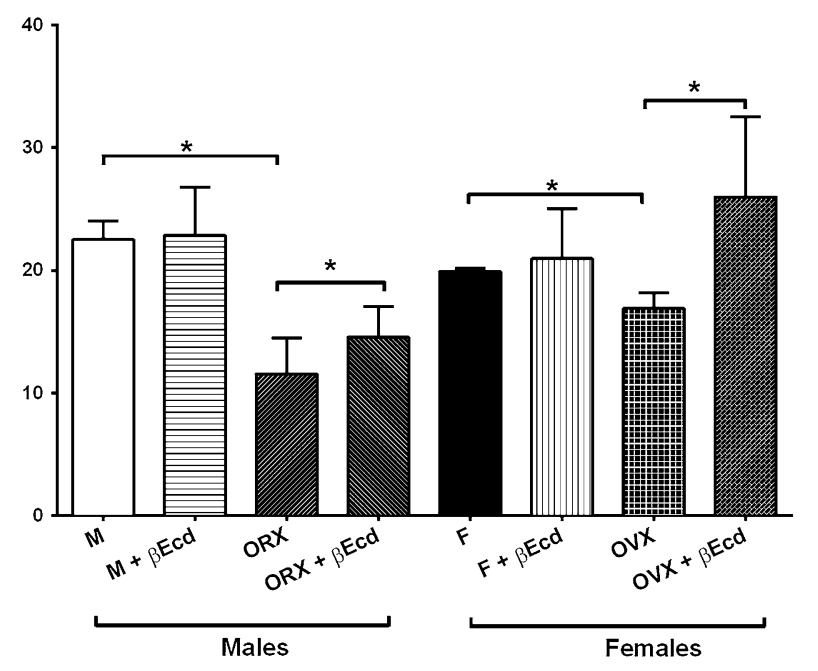

structure measured by micro-CT and bone strength was measured by compression test. $* \mathrm{p}<0.05$ between indicated groups. $\mathrm{M}=$ male; $\mathrm{F}=$ female.

$0.66 \pm 0.1$ in PL and $0.79 \pm 0.2$ in the $\beta E c d$-treated group ( $\mathrm{p}<0.05$ versus PL); and $0.67 \pm 0.01$ in the OVX group and $0.70 \pm 0.03$ in the OVX $+\beta$ Ecd group.

In male mice, cortical bone thickness was $0.182 \pm 0.005$ in PL and $0.204 \pm 0.06$ in the $\beta$ Ecd-treated group ( $p<0.05$ versus PL); and $0.173 \pm 0.005$ in the ORX group ( $p<0.05$ versus PL) and $0.173 \pm 0.003$ in the ORX $+\beta E c d$ group $(p<0.05$ versus PL). In female mice, Ct.Th was $0.174 \pm 0.005$ in PL and $0.211 \pm 0.007$ in the $\beta$ Ecd-treated group $(\mathrm{p}<0.05$ versus $\mathrm{PL})$; and $0.186 \pm$ 0.007 in the OVX group and $0.200 \pm 0.005$ in the OVX + $\beta$ Ecd group (Fig. 3). 
A
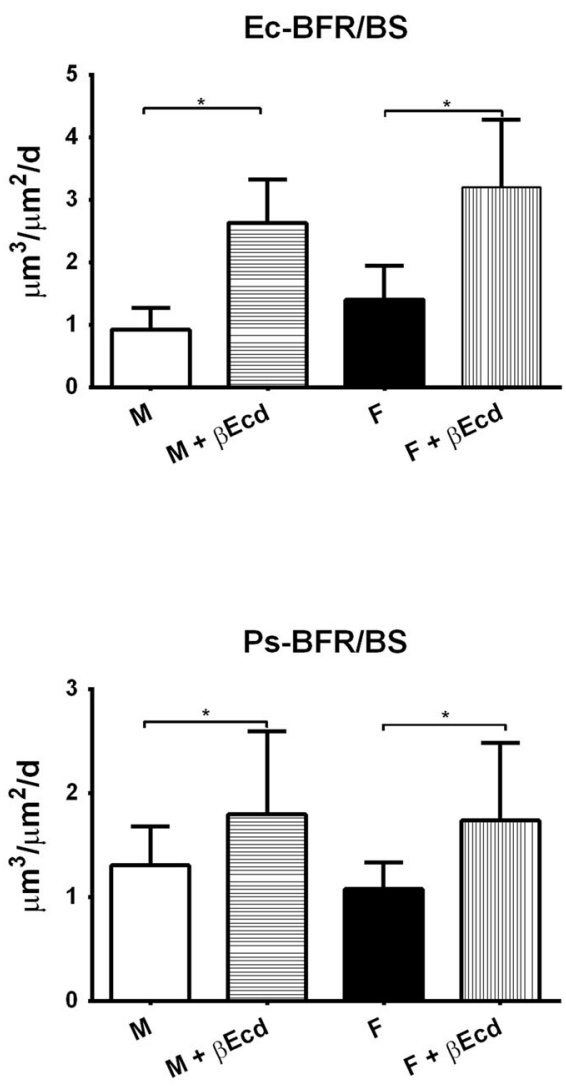

B

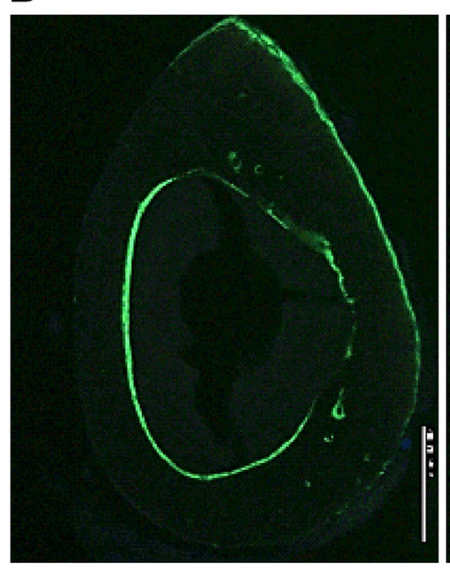

Male

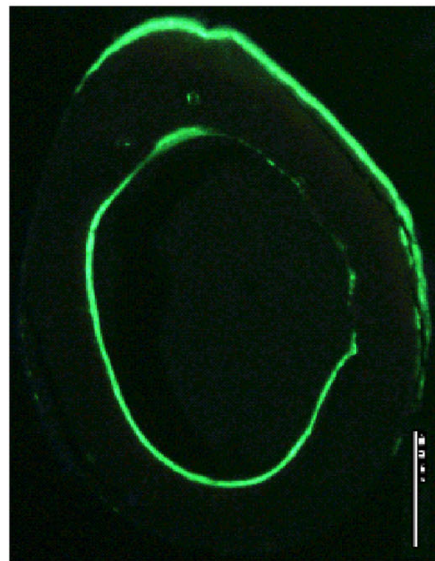

Female

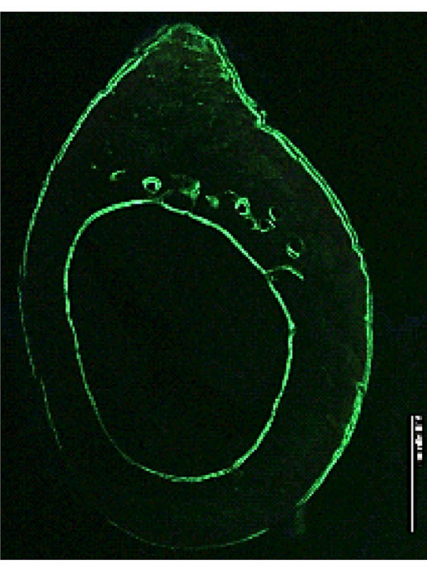

Male $+\beta E c d$

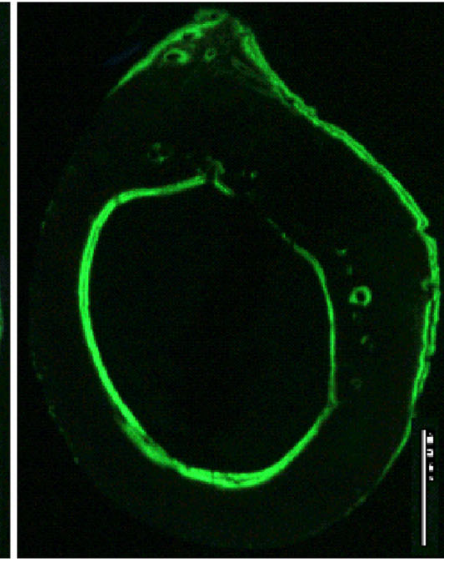

Female $+\beta$ Ecd
Fig. 2A-B $\beta$ Ecd treatment increases cortical bone formation. (A) Bone formation rate measured at the periosteal and endocortical bone surfaces by bone histomorphometry. (B) Representative cross-sectional cortical

Does $\beta$ Ecd Treatment Affect Bone Strength?

\section{Effects of $\beta E c d$ Treatment on Vertebral Bone Strength}

In male mice, the vertebral maximum load was $43 \pm 2$ in $\mathrm{PL}$ and $51 \pm 1$ in the $\beta$ Ecd-treated group $(\mathrm{p}<0.05$ versus $\mathrm{PL})$; and $30 \pm 4$ in the ORX group $(\mathrm{p}<0.05$ versus PL) and $37 \pm 3$ in the ORX $+\beta E c d$ group $(p<0.05$ versus ORX). The vertebral work to failure was $22 \pm 1$ in PL and $23 \pm 4$ in the $\beta E c d-$ treated group; and $11 \pm 3$ in the ORX group ( $<<0.05$ versus PL) and $15 \pm 2$ in the ORX + $\beta$ Ecd group ( $<0.05$ versus ORX) (Fig. 2).

In female mice, the maximum load of the vertebrae was $45 \pm 2$ in PL and $48 \pm 4$ in the $\beta$ Ecd-treated group; and $39 \pm 4$ in the OVX group ( $<<0.05$ versus PL) and $44 \pm 4$ in the OVX $+\beta E c d$ group. The vertebral work to failure was $20 \pm 1$ in PL and $21 \pm 4$ in the $\beta$ Ecd-treated bone sections from the midfemurs in intact male and female mice that were treated with $\beta E c d$ for 21 days. $* p<0.05$ between indicated treatment groups. $\mathrm{M}=$ male; $\mathrm{F}=$ female. Scale bar $=100$ micron.

group; and $17 \pm 1$ in the OVX group ( $<<0.05$ versus PL) and $26 \pm 6$ in the ORX $+\beta$ Ecd group $(\mathrm{p}<0.05$ versus OVX) (Fig. 2).

\section{Effects of $\beta E c d$ Treatment on Cortical Bone Strength}

In male mice, the femoral maximum load was $13 \pm 0.8$ in $\mathrm{PL}$ and $15 \pm 0.3$ in the $\beta$ Ecd-treated group $(\mathrm{p}<0.05$ versus PL); and $13 \pm 0.5$ in the ORX group and $13 \pm 0.5$ in the ORX $+\beta$ Ecd group. The femoral work to failure was $2.5 \pm 0.2$ in PL and $2.8 \pm 0.3$ in the $\beta$ Ecd-treated group ( $\mathrm{p}<0.05$ versus PL); and $2.1 \pm 0.2$ in the ORX group and $2.4 \pm 0.1$ in the ORX $+\beta E c d$ group (Fig. 3).

In female mice, the maximum load of the femurs was $11 \pm 0.5$ in PL and $12 \pm 0.5$ in the $\beta$ Ecd-treated group $(\mathrm{p}<0.05$ versus PL); and $12 \pm 0.5$ in the OVX group and 


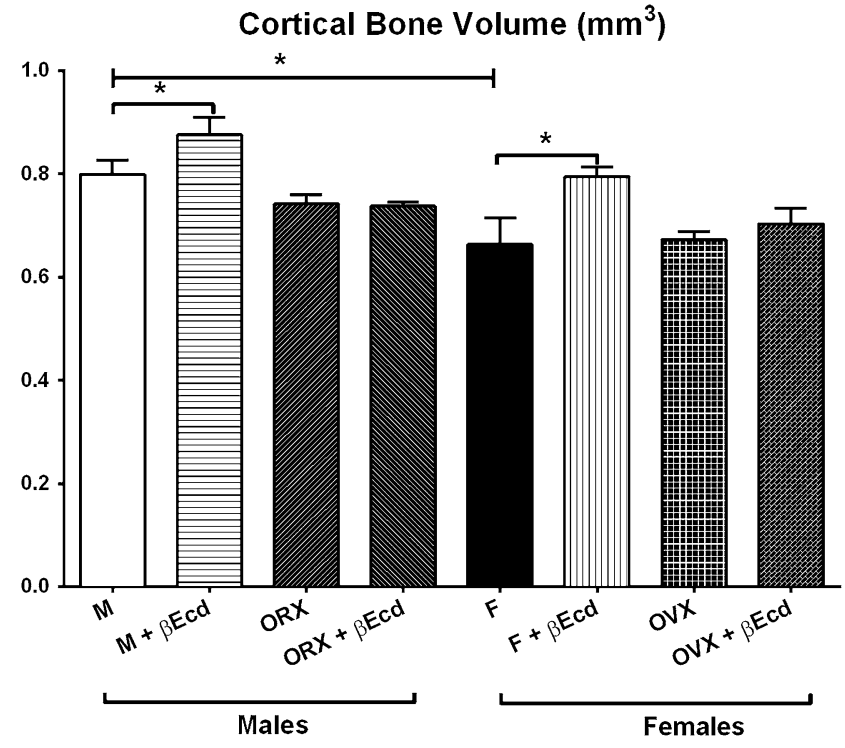

\section{Cortical Bone Thickness (mm)}
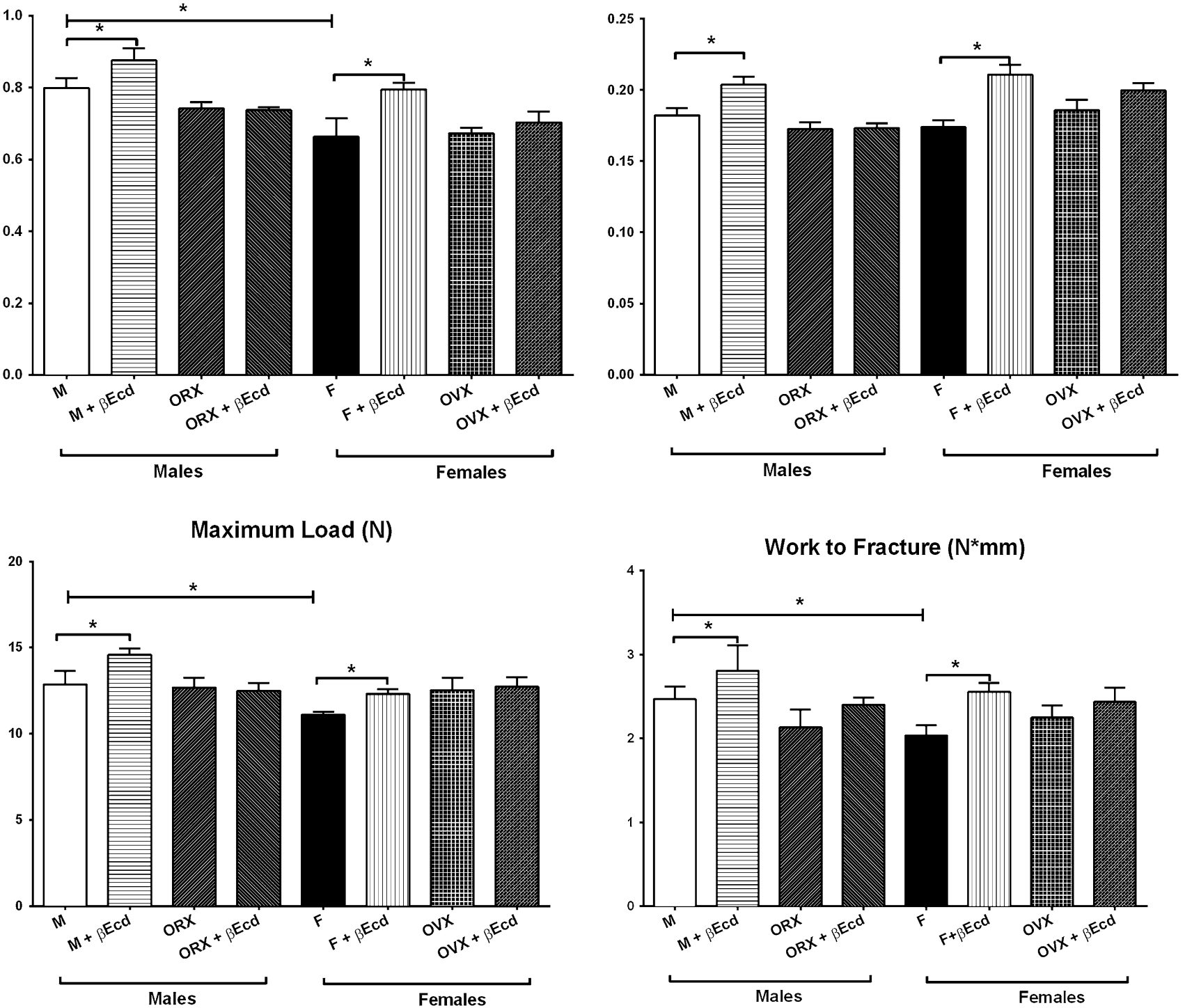

Fig. $3 \beta E c d$ treatment increases cortical bone mass and bone strength. Middle femoral bone structure measured by micro-CT and bone strength was measured by femoral three-point ending test. $* \mathrm{p}<0.05$ between indicated treatment groups. $\mathrm{M}=$ male; $\mathrm{F}=$ female.

$13 \pm 0.5$ in the OVX $+\beta$ Ecd group. The femoral work to failure was $2.0 \pm 0.1$ in PL and $2.6 \pm 0.1$ in the $\beta$ Ecdtreated group ( $\mathrm{p}<0.05$ versus PL); and $2.2 \pm 0.2$ in the OVX group and $2.4 \pm 0.2$ in the ORX $+\beta$ Ecd group (Fig. 3).

\section{Discussion}

Treatment with $\beta$ Ecd increased both trabecular and cortical bone volume and bone strength in both sexes through anabolic mechanisms in gonadal-sufficient mice. In gonadalinsufficient mice, trabecular bone loss was partially prevented with concurrent $\beta E c d$ treatment in the ORX and OVX animals.

This study had a number of limitations. First, we only used one dose of $\beta$-ecdysone and only included one time point. Additionally, we did not evaluate the potential activation or deactivation of hormonal receptors that include estrogen and androgen receptors after $\beta \mathrm{Ecd}$ treatment or if $\beta$-Ecd would alter the sensitivities of the hormonal receptors. Because $\beta$ Ecd is structurally similar to testosterone or estrogen, it is thought to have steroid hormone-like effects including stimulating protein synthesis, promoting carbohydrate and lipid metabolism, alleviating hyperglycemia and hyperlipidemia, having immunologic modulation 
effects, and protecting endothelial cells from apoptosis. However, it was reported that $\beta E c d$ did not bind to the estrogen receptor [35], and its pharmacological effects may not involve estrogen receptor activation. To further examine whether hormones play a role in the effects of $\beta \mathrm{Ecd}$ on bone, we treated the ORX male and OVX female mice with $\beta E c d$. $\beta E c d$ treatment partially prevented trabecular bone loss primarily through further increases in tissue-level bone formation markers and bone formation rates. However, $\beta$ Ecd treatment at the current dose and treatment length failed to have beneficial effects on the cortical bone in hormone-deficient mice. A longer treatment period or dose-dependent study may be necessary to further elucidate whether sex steroid status altered $\beta E c d$ treatment efficacy as far as the skeletal changes are concerned.

\section{Sex Differences in Skeletal Geometry and Bone Strength}

The mice we used gained approximately $10 \%$ body mass during the study period. These Swiss Webster mice normally obtain their peak bone mass by 4 months of age [25, $40,41,43]$. For this reason, the bone development in mice in this study might resemble late pubertal human bone development. We found that female mice had similar vertebral bone mass and strength as the male mice at 3 months of age. These observations were similar to the results of another study performed in C57BL/6 mice [1]. Although the females had higher trabecular bone volume within the vertebral body, the smaller bone size in female mice compared with the male mice may correspond to a lower maximum compression load and the overall bone strength (work to failure) for both trabecular bone (vertebrae) and cortical bone (femoral shafts).

\section{Sex Differences in Response to $\beta$ Ecd Treatment}

Sex is a significant contributing factor to the different therapeutic responses observed between females and males. For example, muscle-derived mesenchymal stem cells obtained from female mouse donors have superior myogenic ability to those from males [13] but lower chondrogenic potential [30]. Supplementation of the culture medium with estrogen increases the osteogenic differentiation of the bone marrow-derived stromal cells from both male and female rat donors [20]. In humans, the prevalence of colony-forming osteogenic units cultured from bone marrow aspirates is significantly reduced with age for women but not for men [20]. One of the main growth factors for peak bone mass acquisition, insulin-like growth factor, is associated with bone mineral density of the spine and hip in postmenopausal women ( $\geq 55$ years) who were not on estrogen but not in aged-matched men [21]. In patients with growth hormone deficiency, men had significantly higher bone gain than women after recombined human growth hormone treatment [21]. In skeletally mature mice, parathyroid hormone has similar osteogenic effects on osteogenesis in vitro but exerts a greater anabolic effect on the trabecular and cortical bone in male mice than in female mice [38].

In the current study, we found $\beta E c d$ increased bone formation rates to similar degrees in male and female mice at the trabecular bone site. The increase in bone formation rate at the trabecular bone surface resulted primarily from greater the osteoblast-forming surface (mineralized surface). Similarly, the percentage increases in cortical bone volume and bone strength (maximum load and work to failure) were similar in intact male mice than in intact female mice that were treated with $\beta E c d$.

In summary, we found that the short-term administration of $\beta$ Ecd in growing intact mice resulted in marked enhancements in both trabecular and cortical bone formation that was associated with significantly increased trabecular and cortical bone volume. These findings imply the potential use of $\beta E c d$ in the bone mass augmentation in growing males and females. Our results indicate that $\beta E c d$ may partially prevent the detrimental effects of gonadectomy on trabecular bone but not on cortical bone. $\beta E c d$ may differ from the other anabolic hormone treatments that have caused some real problems when taken from the laboratory to human models such as serious cardiac complications. However, its efficacy in humans awaits further investigations.

Acknowledgments We would like to thank Dr. Qiujuan Xing from the Department of Science and Technology, Integrative Medicine, Longhua Hospital Shanghai University of Traditional Chinese Medicine, Shanghai, PR China and funding sources from Natural Science Foundation of Shanghai, China 15ZR1441600 (to WD) and the National Natural Science Foundation of China, 81102606 (to QX) for laying the foundation work for this report.

\section{References}

1. Almeida M, Han L, Martin-Millan M, Plotkin LI, Stewart SA, Roberson PK, Kousteni S, O'Brien CA, Bellido T, Parfitt AM, Weinstein RS, Jilka RL, Manolagas SC. Skeletal involution by age-associated oxidative stress and its acceleration by loss of sex steroids. J Biol Chem. 2007;282:27285-27297.

2. Bailey DA, McKay HA, Mirwald RL, Crocker PR, Faulkner RA. A six-year longitudinal study of the relationship of physical activity to bone mineral accrual in growing children: the university of Saskatchewan bone mineral accrual study. J Bone Miner Res. 1999;14:1672-1679.

3. Bathori M. Phytoecdysteroids effects on mammalians, isolation and analysis. Mini Rev Med Chem. 2002;2:285-293. 
4. Bathori M, Toth N, Hunyadi A, Marki A, Zador E. Phytoecdysteroids and anabolic-androgenic steroids-structure and effects on humans. Curr Med Chem. 2008;15:75-91.

5. Beck TJ, Ruff CB, Shaffer RA, Betsinger K, Trone DW, Brodine SK. Stress fracture in military recruits: gender differences in muscle and bone susceptibility factors. Bone. 2000;27:437-444.

6. Bonjour JP, Chevalley T, Ammann P, Slosman D, Rizzoli R. Gain in bone mineral mass in prepubertal girls 3.5 years after discontinuation of calcium supplementation: a follow-up study. Lancet. 2001;358:1208-1212.

7. Boo KH, Lee D, Jeon GL, Ko SH, Cho SK, Kim JH, Park SP, Hong Q, Lee SH, Lee DS, Riu KZ. Distribution and biosynthesis of 20-hydroxyecdysone in plants of Achyranthes japonica Nakai. Biosci Biotechnol Biochem. 2010;74:2226-2231.

8. Cahlikova L, Macakova K, Chlebek J, Host'alkova A, Kulhankova A, Opletal L. Ecdysterone and its activity on some degenerative diseases. Nat Prod Commun. 2011;6:707-718.

9. Cheng DM, Kutzler LW, Boler DD, Drnevich J, Killefer J, Lila MA. Continuous infusion of 20-hydroxyecdysone increased mass of triceps brachii in C57BL/6 mice. Phytother Res. 2013;27:107-111.

10. Chokalingam K, Roforth MM, Nicks KM, McGregor U, Fraser D, Khosla S, Monroe DG. Examination of ERalpha signaling pathways in bone of mutant mouse models reveals the importance of ERE-dependent signaling. Endocrinology. 2012;153:5325-5333.

11. Courteix D, Jaffre C, Lespessailles E, Benhamou L. Cumulative effects of calcium supplementation and physical activity on bone accretion in premenarchal children: a double-blind randomised placebo-controlled trial. Int J Sports Med. 2005;26:332-338.

12. Dai W, Jiang L, Lay YA, Chen H, Jin G, Zhang H, Kot A, Ritchie RO, Lane NE, Yao W. Prevention of glucocorticoid induced bone changes with beta-ecdysone. Bone. 2015;74C:48-57.

13. Deasy BM, Lu A, Tebbets JC, Feduska JM, Schugar RC, Pollett JB, Sun B, Urish KL, Gharaibeh BM, Cao B, Rubin RT, Huard J. A role for cell sex in stem cell-mediated skeletal muscle regeneration: female cells have higher muscle regeneration efficiency. J Cell Biol. 2007;177:73-86.

14. Dinan L. The Karlson Lecture. Phytoecdysteroids: what use are they? Arch Insect Biochem Physiol. 2009;72:126-141.

15. Dinan L, Lafont R. Effects and applications of arthropod steroid hormones (ecdysteroids) in mammals. J Endocrinol. 2006;191:1-8.

16. Duan Y, Turner CH, Kim BT, Seeman E. Sexual dimorphism in vertebral fragility is more the result of gender differences in agerelated bone gain than bone loss. J Bone Miner Res. 2001;16: 2267-2275.

17. Esposito D, Komarnytsky S, Shapses S, Raskin I. Anabolic effect of plant brassinosteroid. FASEB J. 2011;25:3708-3719.

18. Gorelick-Feldman J, MacLean D, Ilic N, Poulev A, Lila MA, Cheng D, Raskin I. Phytoecdysteroids increase protein synthesis in skeletal muscle cells. J Agr Food Chem. 2008;56:3532-3537.

19. Guan M, Yao W, Liu R, Lam KS, Nolta J, Jia J, Panganiban B, Meng L, Zhou P, Shahnazari M, Ritchie RO, Lane NE. Directing mesenchymal stem cells to bone to augment bone formation and increase bone mass. Nat Med. 2012;18:456-462.

20. Hong L, Sultana H, Paulius K, Zhang G. Steroid regulation of proliferation and osteogenic differentiation of bone marrow stromal cells: a gender difference. J Steroid Biochem Mol Biol. 2009;114:180-185.

21. Johansson AG, Engstrom BE, Ljunghall S, Karlsson FA, Burman $\mathrm{P}$. Gender differences in the effects of long term growth hormone (GH) treatment on bone in adults with GH deficiency. J Clin Endocrinol Metab. 1999;84:2002-2007.

22. Johnston CC Jr, Slemenda CW. Determinants of peak bone mass. Osteoporos Int. 1993;3(Suppl 1):54-55.

23. Jones G, Dwyer T. Bone mass in prepubertal children: gender differences and the role of physical activity and sunlight exposure. J Clin Endocrinol Metab. 1998;83:4274-4279.
24. Kapur P, Wuttke W, Jarry H, Seidlova-Wuttke D. Beneficial effects of beta-Ecdysone on the joint, epiphyseal cartilage tissue and trabecular bone in ovariectomized rats. Phytomedicine. 2010;17:350-355.

25. Lane NE, Yao W, Balooch M, Nalla RK, Balooch G, Habelitz S, Kinney JH, Bonewald LF. Glucocorticoid-treated mice have localized changes in trabecular bone material properties and osteocyte lacunar size that are not observed in placebo-treated or estrogen-deficient mice. J Bone Miner Res. 2006;21:466-476.

26. Liao DJ, Dickson RB. Roles of androgens in the development, growth, and carcinogenesis of the mammary gland. J Steroid Biochem Mol Biol. 2002;80:175-189.

27. Manolagas SC, O'Brien CA, Almeida M. The role of estrogen and androgen receptors in bone health and disease. Nat Rev Endocrinol. 2013;9:699-712.

28. Manson JE, Chlebowski RT, Stefanick ML, Aragaki AK, Rossouw JE, Prentice RL, Anderson G, Howard BV, Thomson CA, LaCroix AZ, Wactawski-Wende J, Jackson RD, Limacher M, Margolis KL, Wassertheil-Smoller S, Beresford SA, Cauley JA, Eaton CB, Gass M, Hsia J, Johnson KC, Kooperberg C, Kuller LH, Lewis CE, Liu S, Martin LW, Ockene JK, O'Sullivan MJ, Powell LH, Simon MS, Van Horn L, Vitolins MZ, Wallace RB. Menopausal hormone therapy and health outcomes during the intervention and extended poststopping phases of the Women's Health Initiative randomized trials. JAMA. 2013;310:1353-1368.

29. Matkovic V, Goel PK, Badenhop-Stevens NE, Landoll JD, Li B, Ilich JZ, Skugor M, Nagode LA, Mobley SL, Ha EJ, Hangartner TN, Clairmont A. Calcium supplementation and bone mineral density in females from childhood to young adulthood: a randomized controlled trial. Am J Clin Nutr. 2005;81:175-188.

30. Matsumoto T, Kubo S, Meszaros LB, Corsi KA, Cooper GM, Li G, Usas A, Osawa A, Fu FH, Huard J. The influence of sex on the chondrogenic potential of muscle-derived stem cells: implications for cartilage regeneration and repair. Arthritis Rheum. 2008;58: 3809-3819.

31. Orwoll ES, Belknap JK, Klein RF. Gender specificity in the genetic determinants of peak bone mass. J Bone Miner Res. 2001;16:1962-1971.

32. Ralston $\mathrm{SH}$, de Crombrugghe B. Genetic regulation of bone mass and susceptibility to osteoporosis. Genes Dev. 2006;20:2492-2506.

33. Roehm E. A reappraisal of women's health initiative estrogenalone trial: long-term outcomes in women 50-59 years of age. Obstet Gynecol Int. 2015;2015:713295.

34. Rossouw JE, Anderson GL, Prentice RL, LaCroix AZ, Kooperberg C, Stefanick ML, Jackson RD, Beresford SA, Howard BV, Johnson KC, Kotchen JM, Ockene J, Writing Group for the Women's Health Initiative I. Risks and benefits of estrogen plus progestin in healthy postmenopausal women: principal results From the Women's Health Initiative randomized controlled trial. JAMA. 2002;288:321-333.

35. Seidlova-Wuttke D, Christel D, Kapur P, Nguyen BT, Jarry H, Wuttke W. Beta-ecdysone has bone protective but no estrogenic effects in ovariectomized rats. Phytomedicine. 2010;17:884-889.

36. Truman JW. Hormonal control of insect ecdysis: endocrine cascades for coordinating behavior with physiology. Vitam Horm. 2005;73:1-30.

37. Turner $\mathrm{CH}$, Burr DB. Basic biomechanical measurements of bone: a tutorial. Bone. 1993;14:595-608.

38. Wang Y, Sakata T, Elalieh HZ, Munson SJ, Burghardt A, Majumdar S, Halloran BP, Bikle DD. Gender differences in the response of CD-1 mouse bone to parathyroid hormone: potential role of IGF-I. J Endocrinol. 2006;189:279-287.

39. Ward KA, Roberts SA, Adams JE, Lanham-New S, Mughal MZ. Calcium supplementation and weight bearing physical activitydo they have a combined effect on the bone density of pre-pubertal children? Bone. 2007;41:496-504. 
40. Weinstein RS, Jia D, Powers CC, Stewart SA, Jilka RL, Parfitt AM, Manolagas SC. The skeletal effects of glucocorticoid excess override those of orchidectomy in mice. Endocrinology. 2004;145:1980-1987.

41. Weinstein RS, Jilka RL, Almeida M, Roberson PK, Manolagas SC. Intermittent parathyroid hormone administration counteracts the adverse effects of glucocorticoids on osteoblast and osteocyte viability, bone formation, and strength in mice. Endocrinology. 2010;151:2641-2649.

42. Yao W, Cheng Z, Koester KJ, Ager JW, Balooch M, Pham A, Chefo S, Busse C, Ritchie RO, Lane NE. The degree of bone mineralization is maintained with single intravenous bisphosphonates in aged estrogen-deficient rats and is a strong predictor of bone strength. Bone. 2007;41:804-812.

43. Yao W, Cheng Z, Pham A, Busse C, Zimmermann EA, Ritchie RO, Lane NE. Glucocorticoid-induced bone loss in mice can be reversed by the actions of parathyroid hormone and risedronate on different pathways for bone formation and mineralization. Arthritis Rheum. 2008;58:3485-3497.

44. Yao W, Cheng Z, Shahnazari M, Dai W, Johnson ML, Lane NE. Overexpression of secreted frizzled-related protein 1 inhibits bone formation and attenuates parathyroid hormone bone anabolic effects. J Bone Miner Res. 2010;25:190-199.

45. Yao W, Dai W, Shahnazari M, Pham A, Chen Z, Chen H, Guan $\mathrm{M}$, Lane NE. Inhibition of the progesterone nuclear receptor during the bone linear growth phase increases peak bone mass in female mice. PloS One. 2010;5:e11410.

46. Yao W, Guan M, Jia J, Dai W, Lay YA, Amugongo S, Liu R, Olivos D, Saunders M, Lam KS, Nolta J, Olvera D, Ritchie RO, Lane NE. Reversing bone loss by directing mesenchymal stem cells to bone. Stem Cells. 2013;31:2003-2014. 